\title{
LCST-type phase behavior of poly(2-chloroethyl vinyl ether-alt-maleic anhydride) in $n$-butyl acetate
}

\author{
Zhenjie Liu ${ }^{1}$, Yongliang Guo ${ }^{1,2}$ and Katsuhiro Inomata ${ }^{1}$
}

Novel polymer solutions exhibiting lower critical solution temperatures (LCSTs) have been studied. An alternating copolymer of 2-chloroethyl vinyl ether and maleic anhydride was synthesized through free-radical solution polymerization. This copolymer can exhibit LCST-type phase behavior in $n$-butyl acetate (BuAc) under relatively mild conditions at temperatures sufficiently below its boiling point. The effects of molecular weight, polymer concentration and addition of cosolvent on the polymer solution's cloud point temperature $\left(T_{\mathrm{cp}}\right)$ were investigated. The $T_{\mathrm{cp}}$ value was nearly constant over a wide range of concentrations and increased when the polymer concentration was reduced below a certain value. The experimental LCST-type phase diagram can be reasonably described by Flory-Huggins theory. The addition of non-solvents could reduce the $T_{\mathrm{cp}}$ of the polymer solution in BuAc, whereas the addition of good solvents could increase the $T_{\mathrm{cp}}$. These LCST-type phase behaviors may be attributed to specific polar interactions between the polymer and the solvent.

Polymer Journal (2011) 43, 676-682; doi:10.1038/pj.2011.41; published online 25 May 2011

Keywords: cloud point; lower critical solution temperature (LCST); mild conditions; organic media; polymer solution; thermoresponsive polymers

\section{INTRODUCTION}

Lower critical solution temperature (LCST)-type phase behavior in polymer solutions has been attracting a great deal of attention over the past decade. Polymers that exhibit LCST are a class of stimuli-sensitive polymers that are soluble at temperatures below the LCST and become insoluble above the LCST. Many studies have focused on LCST-type phase behavior in aqueous polymer solutions, and many theories and applications have been developed. ${ }^{1-3}$ Today, LCST-type phase behavior of polymers in nonaqueous media is also attracting interest as an opportunity for research and development of smart materials. For example, LCST polymer solutions of thermoresponsive polymer/ionic liquid systems have been reported. ${ }^{4-7}$

Conventional LCST polymer solutions in organic media have critical temperatures that are higher than the boiling points (BPs) of the solvents. ${ }^{8-14}$ These reported systems can exhibit LCST-type phase behavior under some extreme conditions, for example, in sealed highpressure cells above the $\mathrm{BP}$ of the solvent or using considerably highmolecular-weight polymers. Some theories have been proposed to explain or predict this type of LCST-type phase behavior. ${ }^{15-17}$ In freevolume theories, the difference between the densities or the expansion coefficients of the polymer and the solvent above the solvent's BP is proposed to cause phase separation at elevated temperatures. ${ }^{17}$ Because these conditions are inconvenient to study, a novel polymer/organic media solution that can present LCST under mild conditions is expected to be discovered. Recently, a few of these novel polymer solution systems in organic media have been reported. ${ }^{18-20}$ For example, polymers with certain unique structures or chemical compositions can exhibit LCST-type phase behavior. Fluoroalkyl-end-capped polymers present LCST behavior that may be primarily related to the balance between the oleophilic character of the adamantyl segments and the oleophobic character of the fluoroalkyl groups. ${ }^{18}$ Thermally reversible, heat-set gel-like networks in organic media with LCST characteristics were developed by combining elements of one-dimensional metal complexes and mesoscopic supramolecular assemblies. ${ }^{19}$ Poly(vinyl ether) with ionic liquid pendants of imidazolium or pyridinium salt can also undergo sensitive LCST-type phase separation in organic media. ${ }^{20}$

Herein, we report a novel polymer solution in common organic media that can present LCST behavior under mild conditions. As has been reported in our recent communication, ${ }^{21}$ the alternating copolymer of 2-chloroethyl vinyl ether (CVE) and maleic anhydride (MA) known as poly(2-chloroethyl vinyl ether-alt-maleic anhydride), henceforth P(CVE-MA), can exhibit LCST-type phase separation in $n$-butyl acetate $(\mathrm{BuAc})$ with a critical temperature sufficiently lower than the $\mathrm{BP}$ of BuAc. In this paper, the detailed phase behavior of BuAc solutions of $\mathrm{P}$ (CVE-MA) with various molecular weights will be described, and the effects of various cosolvents on LCST behavior will also be presented.

${ }^{1}$ Department of Materials Science and Engineering, Nagoya Institute of Technology, Nagoya, Japan and ${ }^{2}$ Department of Materials Science and Engineering, Beijing University of Chemical Technology, Beijing, China

Correspondence: Professor K Inomata, Department of Materials Science and Engineering, Nagoya Institute of Technology, Gokiso-cho, Showa-ku, Nagoya 466-8555, Japan.

E-mail: inomata.katsuhiro@nitech.ac.jp

Received 20 October 2010; revised 21 February 2011; accepted 24 March 2011; published online 25 May 2011 


\section{EXPERIMENTAL PROCEDURE}

\section{Materials}

Benzene (Nacalai tesque, Kyoto, Japan; 99.5\%), toluene (Nacalai tesque; 99.5\%), cyclohexane (Nacalai tesque; 99.5\%), dimethylsulfoxide (DMSO; Kishida Chemical; 99\%), 2-hexanone (TCI, Tokyo, Japan; >98.0\%), sodium hydroxide ( $\mathrm{NaOH}$; Nacalai tesque; $97 \%)$, anhydrous sodium sulfate $\left(\mathrm{Na}_{2} \mathrm{SO}_{4}\right.$; Nacalai tesque; 97\%), calcium hydride $\left(\mathrm{CaH}_{2}\right.$; Nacalai tesque; EP) and 2,2'azobisisobutyronitrile (Wako, Osaka, Japan; $>98 \%$ ) were used as received. CVE (TCI; >97.0\%) was washed three times with an equal volume of water made slightly alkaline with $\mathrm{NaOH}$, dried with $\mathrm{Na}_{2} \mathrm{SO}_{4}$, refluxed in the presence of $\mathrm{CaH}_{2}$ for $2 \mathrm{~h}$ and distilled under reduced pressure. MA (TCI; $>99.0 \%$ ) was recrystallized in benzene. Methyl ethyl ketone (TCI; >99.0\%) was refluxed in the presence of $\mathrm{CaH}_{2}$ for $2 \mathrm{~h}$, distilled under reduced pressure and kept in the presence of a molecular sieve. Propyl acetate (TCI; > 98.0\%), BuAc (Aldrich, St Louis, MO, USA; ACS reagent; $\geqslant 99.5 \%$ ), 1,2-dichloroethane (Wako; $>99.5 \%$ ) and tetrahydrofuran (Wako; $>99.5 \%$ ) were distilled before use.

\section{Synthesis of copolymer}

MA and CVE were copolymerized by free-radical solution polymerization. Typically, specific amounts of MA, CVE, 2,2'-azobisisobutyronitrile and solvent were added to a $50 \mathrm{ml}$ three-neck flask equipped with a condenser and a nitrogen gas inlet. The reaction solution was stirred for a specified time at a given temperature. The resultant polymer was precipitated in diethyl ether and dried in vacuum at $100{ }^{\circ} \mathrm{C}$ for at least $8 \mathrm{~h}$.

\section{Gel permeation chromatograph}

The molecular weight of the prepared copolymer was determined by gel permeation chromatograph using two columns of TSKgel, $\alpha-3000$ and $\alpha-5000$, connected to an SD-8022 system (Tosoh, Tokyo, Japan) with a $1.0 \mathrm{ml} \mathrm{min}{ }^{-1} \mathrm{~N}, \mathrm{~N}$-dimethylformamide/lithium bromide flow rate (the concentration of lithium bromide was $15 \mathrm{mgl}^{-1}$ ). Polystyrene standards were used to calibrate the molecular weight during measurement.

\section{Preparation of polymer solutions}

Polymer solutions in BuAc were prepared by direct dissolution of specified amounts of polymer in BuAc. The bottle containing the polymer and BuAc was placed in an oven at $60^{\circ} \mathrm{C}$ for about $8 \mathrm{~h}$ to dissolve the polymer. The bottle containing the polymer solution was then kept in a refrigerator at about $3{ }^{\circ} \mathrm{C}$ until measurements were made.

Polymer solutions in BuAc/cosolvent were prepared as follows: a certain amount of the polymer was added to BuAc, the bottle was kept in an oven at $60^{\circ} \mathrm{C}$ for about $8 \mathrm{~h}$, and then a specified amount of the cosolvent was added to the prepared polymer solution. The bottle containing the polymer solution in BuAc/cosolvent was kept in a refrigerator at about $3{ }^{\circ} \mathrm{C}$ until measurements were performed.

The polymers were measured immediately after polymerization to prevent degradation, oxidation or water absorption.

\section{Light scattering}

The thermoresponsive phase behavior of the polymer solution was characterized using a light scattering technique. The scattered light intensity $\left(I_{\mathrm{s}}\right)$ at a fixed angle of $90^{\circ}$ and at various temperatures was measured using a laboratory-made apparatus equipped with an ALV/SO-SIPD detector (ALV, Langen, Germany) and a He-Ne laser (wavelength $\lambda_{0}=633 \mathrm{~nm}$ ). ${ }^{22}$ The sample solutions were optically purified by a Millipore filter (Millipore, Billerica, MA, USA) with a nominal pore size of $1.0 \mu \mathrm{m}$ and then transferred into the optical tube. The heating and cooling rates of the system were both about $0.2^{\circ} \mathrm{C} \mathrm{min}^{-1}$. The $I_{\mathrm{s}}$ of the polymer solution was measured immediately when the temperature of the system reached the desired temperature.

\section{RESULTS AND DISCUSSION}

Synthesis of copolymers

CVE has an electron-releasing alkoxyl group and is usually used in cationic polymerization, ${ }^{23-27}$ whereas MA contains an electronaccepting carboxylic anhydride group. These two groups can form charge transfer complexes of donor-acceptor monomer systems in which MA and CVE act as the accepter monomer and the donor monomer, respectively. ${ }^{28}$ It is well known that alternating copolymers of vinyl ether and MA can be formed in free-radical polymerization. ${ }^{29-32}$ Our previous report ${ }^{21}$ used ${ }^{1} \mathrm{H}$ nuclear magnetic resonance to show that the molar composition of MA and CVE of the formed copolymer was $1: 1$, and the ${ }^{13} \mathrm{C}$ nuclear magnetic resonance spectrum suggested that these monomers were alternately polymerized.

Copolymers with different weight-averaged molecular weights $\left(M_{\mathrm{w}}\right)$ were synthesized. The reaction conditions and the $M_{\mathrm{w}}$ values measured through gel permeation chromatograph are listed in Table 1. The various copolymers are designated $\mathrm{P}(\mathrm{CVE}-\mathrm{MA})-1,-2,-3,-4$ and -5. Higher molecular weight polymers $\left(M_{\mathrm{w}}=36400,77200\right.$ and $92200 \mathrm{~g} \mathrm{~mol}^{-1}$ ) were synthesized in methyl ethyl ketone, and polymers with lower $M_{\mathrm{w}}\left(7700\right.$ and $17500 \mathrm{~g} \mathrm{~mol}^{-1}$ ) were synthesized in tetrahydrofuran with much more initiator added.

\section{LCST-type phase behavior of polymer solution}

The temperature-sensitive behavior of the polymer solution can be studied through various methods, such as turbidity, differential scanning calorimetry, light scattering measurements, viscometry and fluorescence. ${ }^{3}$ In our research, the temperature-sensitive behavior was characterized using the scattered light intensity $I_{\mathrm{S}}$ at a fixed $90^{\circ}$ angle. Figure 1 shows that the $I_{\mathrm{s}}$ of the polymer solution increased abruptly as the temperature increased above a certain temperature. Above a certain polymer concentration $(>0.1 \mathrm{wt} \%)$, the polymer solution became visually turbid, meaning that phase separation occurred above a certain temperature. This point is called the cloud point temperature $\left(T_{\mathrm{cp}}\right)$. In other words, the polymer is soluble below $T_{\mathrm{cp}}$ and insoluble above $T_{\mathrm{cp}}$, which is characteristic of LCST-type phase behavior in a polymer solution. In our experiment, $T_{\mathrm{cp}}$ is defined from

Table 1 Polymerization conditions of P(CVE-MA) with different molecular weights

\begin{tabular}{|c|c|c|c|c|c|}
\hline Condition & $P(C V E-M A)-1$ & $P(C V E-M A)-2$ & $P(C V E-M A)-3$ & $P(C V E-M A)-4$ & $P(C V E-M A)-5$ \\
\hline Solvent & MEK & MEK & MEK & THF & THF \\
\hline $\mathrm{MA}(\mathrm{g})$ & 4.9 & 4.9 & 2.452 & 4.9 & 2.452 \\
\hline CVE (g) & 5.3 & 5.3 & 2.615 & 5.3 & 2.615 \\
\hline AIBN (g) & 0.0200 & 0.0248 & 0.04 & 0.04 & 0.4 \\
\hline Solvent (g) & 40 & 20 & 55 & 40 & 100 \\
\hline Reaction temperature $\left({ }^{\circ} \mathrm{C}\right)$ & 60 & 70 & 70 & 60 & 60 \\
\hline Reaction time $(\mathrm{h})$ & 6 & 2 & 2 & 6 & 6 \\
\hline$M_{\mathrm{w}}\left(\mathrm{g} \mathrm{mol}^{-1}\right)$ & 77200 & 92200 & 36400 & 17500 & 7700 \\
\hline$M_{\mathrm{w}} / M_{\mathrm{n}}$ & 1.87 & 1.90 & 1.42 & 2.77 & 1.48 \\
\hline Conversion (\%) & 57.8 & 58.8 & 52.5 & 90.7 & 40.5 \\
\hline
\end{tabular}

Abbreviations: AIBN, 2,2'-azobisisobutyronitrile; CVE, 2-chloroethyl vinyl ether; MA, maleic anhydride; MEK, methyl ethyl ketone; THF, tetrahydrofuran. 


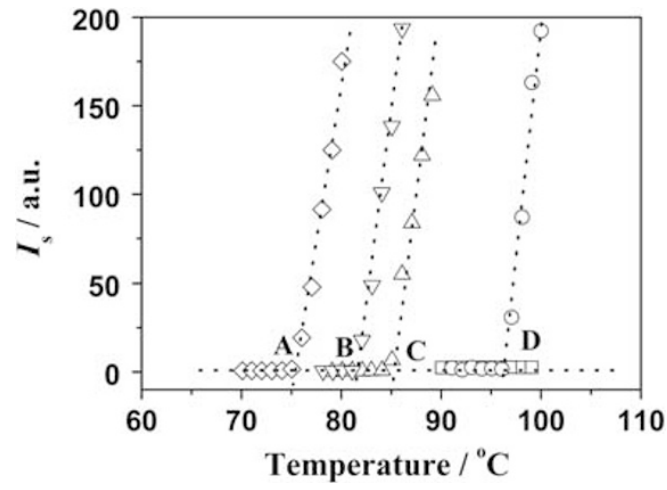

Figure 1 Temperature dependence of the scattered light intensity $\left(I_{\mathrm{s}}\right)$ of polymer/n-butyl acetate solutions with different weight-averaged molecular weights. $(\diamond) \quad 0.05 \mathrm{wt} \%$ solution of P(CVE-MA)-2 $\left(M_{\mathrm{w}}=92200\right), \quad(\nabla)$ $0.05 \mathrm{wt} \%$ solution of P(CVE-MA)-1 $\left(M_{w}=77200\right),(\triangle) 0.05 \mathrm{wt} \%$ solution of P(CVE-MA)-3 $\left(M_{\mathrm{w}}=36400\right)$, (O) $1 \mathrm{wt} \%$ solution of P(CVE-MA)-4 $\left(M_{\mathrm{w}}=17500\right)$ and $(\square) 10 \mathrm{wt} \%$ solution of P(CVE-MA)-5 $\left(M_{\mathrm{w}}=7700\right)$. The points $A, B, C$ and $D$ indicate the $T_{\mathrm{cp}}$ of each solution, and the broken lines are tangent lines for evaluating $T_{\mathrm{cp}}$.

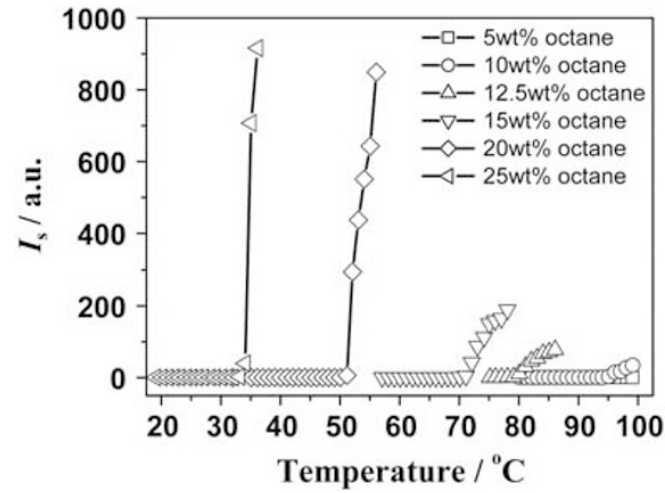

Figure 2 Temperature dependence of scattered light intensity $\left(I_{\mathrm{s}}\right)$ of P(CVEMA)- 5 solutions with $1 \mathrm{wt} \%$ polymer concentration in a solvent mixture of $n$-butyl acetate and $n$-octane. The weight percentage of $n$-octane is indicated in the graph.

the temperature dependence of $I_{\mathrm{s}}$ in Figure 1 , that is, $T_{\mathrm{cp}}$ is the temperature at which the tangents to the lines in the higher and lower temperature regimes intersect (the points A, B, C and D for different polymer solutions in Figure 1).

The value of $T_{\mathrm{cp}}$ decreased as the $M_{\mathrm{w}}$ of the polymer increased. The higher molecular weight polymers (P(CVE-MA)-1, 2 and 3) exhibited LCST-type phase behavior at a relative low $T_{\mathrm{cp}}\left(<90^{\circ} \mathrm{C}\right)$ and low polymer concentrations. In contrast, the $T_{\mathrm{cp}}$ of the polymer $\mathrm{P}(\mathrm{CVE}-$ $\mathrm{MA})-4$, with a lower molecular weight, was about $97^{\circ} \mathrm{C}$ even at a relatively high polymer concentration of $1 \mathrm{wt} \%$. The lowest molecular weight polymer, $\mathrm{P}(\mathrm{CVE}-\mathrm{MA})-5$, did not exhibit thermoresponsive phase behavior until $99^{\circ} \mathrm{C}$ (the upper limit of the apparatus) even at a concentration of $10 \mathrm{wt} \%$. To evaluate the $T_{\mathrm{cp}}$ of $\mathrm{P}(\mathrm{CVE}-\mathrm{MA})-5$ in pure $\mathrm{BuAc}$, the non-solvent $n$-octane was added to the BuAc-polymer solution. As shown in the latter part of this report, the addition of a cosolvent can influence $T_{\mathrm{cp}}$ in a manner dependent on the solvent quality of the cosolvent. Figure 2 indicates that a small amount of $n$-octane ( $5 \mathrm{wt} \%$ ) added to the BuAc-polymer solution did not induce thermoresponsive behavior below $100^{\circ} \mathrm{C}$. As the amount of $n$-octane in the mixed solvent increased over $10 \mathrm{wt} \%$, LCST-type phase behavior was recognized, and further increasing the $n$-octane content of the

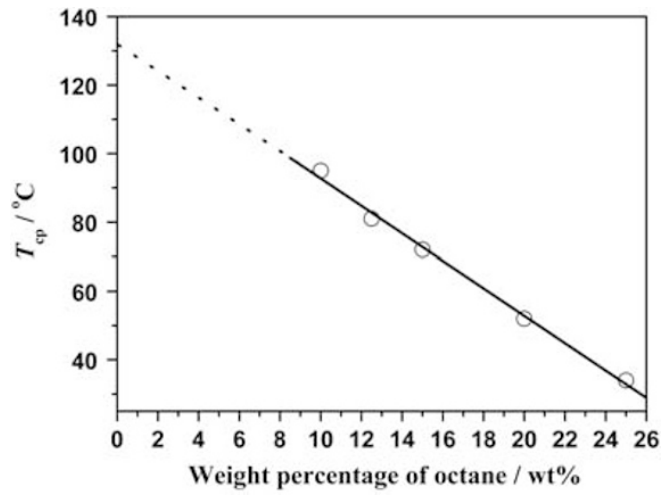

Figure 3 Octane weight percentage dependence of the $T_{c p}$ of the P(CVEMA)-5 solution.

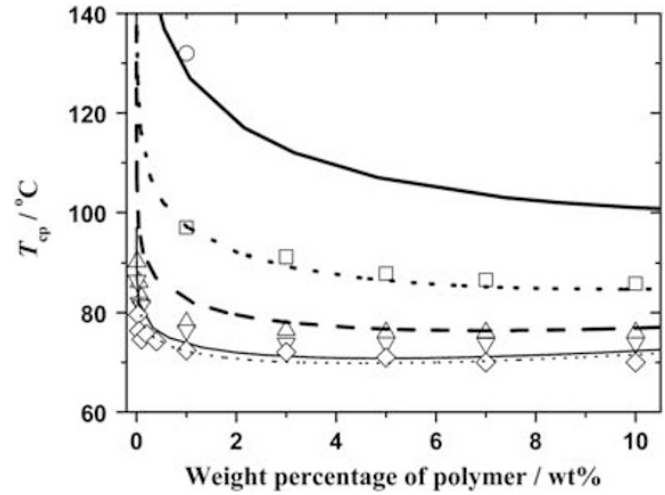

Figure $4 T_{\mathrm{cp}}$ of polymer/n-butyl acetate solutions at different polymer concentrations. $M_{\mathrm{w}}$ is $(\bigcirc) 7700,(\square) 17500,(\triangle) 36400,(\nabla) 77200$ and $(\diamond) 92200 \mathrm{~g} \mathrm{~mol}^{-1}$. Binodal curves for these polymers were calculated by using Equations (5) and (6) and are presented as solid $(P=38)$, broken $(P=86)$, dashed $(P=178)$, thin solid $(P=378)$ and thin broken $(P=451)$ lines, respectively.

mixed solvent caused the $I_{\mathrm{s}}$ ratio to increase and $T_{\mathrm{cp}}$ to be reduced. In Figure 3, the $T_{\mathrm{cp}}$ values of $1 \mathrm{wt} \%$ polymer solutions in BuAc/n-octane are plotted against the $n$-octane content in the mixed solution. $T_{\mathrm{cp}}$ decreased linearly with increasing $n$-octane content, and the extrapolated line intersects the vertical axis at about $132^{\circ} \mathrm{C}$, which is higher than the $\mathrm{BP}$ of BuAc. This value could provide information about the $T_{\mathrm{cp}}$ of $\mathrm{P}(\mathrm{CVE}-\mathrm{MA})-5$ in pure BuAc with a polymer concentration of $1 \mathrm{wt} \%$.

Plots of $T_{\mathrm{cp}}$ versus polymer concentration of the BuAc-polymer solutions are shown in Figure 4. The value of $T_{\mathrm{cp}}$ increased as the $M_{\mathrm{w}}$ of P(CVE-MA) decreased. Similar molecular weight dependence of $T_{\text {cp }}$ or LCST behavior has frequently been observed in aqueous polymer solutions. ${ }^{33-35}$ As mentioned above, the lowest molecular weight P(CVE-MA)-5 did not exhibit thermoresponsive phase behavior even in a $10 \mathrm{wt} \%$ solution, and the value of evaluated $T_{\mathrm{cp}}$ indicated in Figure 4 was derived from extrapolating the measurements shown in Figure 3. The $T_{\text {cp }}$ of $\mathrm{P}(\mathrm{CVE}-\mathrm{MA})-4 / \mathrm{BuAc}$ was much higher than that of the higher molecular weight polymers $\mathrm{P}(\mathrm{CVE}-$ MA) $-1,-2$, and -3 and varies over a wide range of polymer concentrations from 1 to $10 \mathrm{wt} \%$. The molecular weight dependence of $T_{\mathrm{cp}}$ became weaker as the $M_{\mathrm{w}}$ of the polymer increased to higher values. For the higher molecular weight polymers, $T_{\mathrm{cp}}$ initially decreased significantly as the polymer concentration increased and then converged to an almost constant value above a certain polymer concentration 
( $>1 \mathrm{wt} \%$ ). Similar dependences of $T_{\mathrm{cp}}$ on polymer concentration have been reported in other water-soluble polymers. ${ }^{36-39}$

It should be noted that the $T_{\mathrm{cp}}$ of $\mathrm{P}(\mathrm{CVE}-\mathrm{MA}) / \mathrm{BuAc}$ at higher $M_{\mathrm{w}}$ is sufficiently below the $\mathrm{BP}$ of $\mathrm{BuAc}\left(126^{\circ} \mathrm{C}\right)$ such that this LCST phase behavior is not caused by the free-volume difference between the polymer and solvent but instead probably originates from some specific interaction between the polymer and the solvent. This kind of phase behavior in polymer solutions can be conventionally described by the Flory-Huggins $(\mathrm{F}-\mathrm{H})$ lattice model based on mean-field theory in which the chemical potential of the solvent (1) and the polymer (2) are expressed by Equations (1) and (2), respectively. The molecular weights of the polymers are considered to be monodisperse.

$$
\begin{aligned}
& \mu_{1}-\mu_{1}^{0}=\Delta \mu_{1}=R T\left\{\ln (1-\phi)+\left(1-\frac{1}{P}\right) \phi+\chi \phi^{2}\right\} \\
& \mu_{2}-\mu_{2}^{0}=\Delta \mu_{2}=R T\left\{\ln \phi-(P-1)(1-\phi)+\chi P(1-\phi)^{2}\right\}
\end{aligned}
$$

In these equations, $R$ is the gas constant, $T$ is the absolute temperature, $P$ is the number of segments per polymer chain and $\phi$ is the volume fraction of the polymer in solution. $\chi$ is the thermodynamic segmental interaction parameter between the polymer and the solvent, and its temperature dependence is conventionally assumed to follow the Shultz-Flory equation ${ }^{40}$ shown in Equation (3).

$$
\chi(T)=\frac{1}{2}-\psi\left(1-\frac{\Theta}{T}\right)
$$

In Equation (3), $\Theta$ is the theta temperature and $\psi$ is the entropy parameter. The lower molecular weight polymers revealed higher critical temperatures; this finding means that the apparent $\chi$ value becomes larger as the temperature increases, so the sign of the parameter $\psi$ must be negative. According to Equation (3), $T_{\mathrm{cp}}$ at the critical point $T_{\mathrm{c}}$ can be calculated from Equation (4). ${ }^{40}$

$$
\frac{1}{T_{\mathrm{c}}}=\frac{1}{\Theta}+\frac{1}{\Theta \psi}\left(\frac{1}{\sqrt{P}}+\frac{1}{2 P}\right)
$$

Because the minimum value of $T_{\mathrm{cp}}$ for each polymer in Figure 4 can be regarded as its critical point, the inverse of the minimum $T_{\mathrm{cp}}$ was plotted against $1 / \sqrt{P}+1 / 2 P$ and displayed in Figure 5. $P$ was evaluated as $M_{\mathrm{w}} / M_{0}$, where $M_{0}=204.6$ is the molecular weight of the repeating unit of $\mathrm{P}(\mathrm{CVE}-\mathrm{MA})$. The derived values of the intercept and slope of the straight line in Figure 5 can be related to the parameters in Equations (3) and (4) and give $\Theta=333 \mathrm{~K}$ and $\psi=-1.62$. The value of $\Theta=333 \mathrm{~K}$ means that BuAc is a good solvent for P(CVE-MA) below

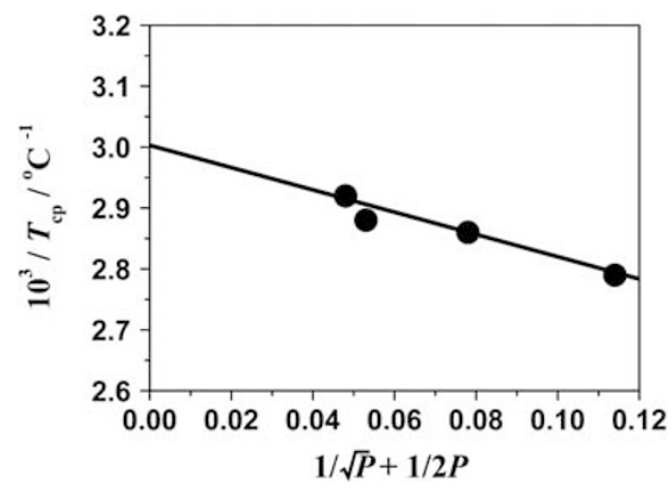

Figure 5 Plot of $1 / T_{\mathrm{cp}}$ versus $(1 / \sqrt{p}+1 / 2 P)$.
$60{ }^{\circ} \mathrm{C}(\chi<1 / 2)$. Above $60^{\circ} \mathrm{C}(\chi>1 / 2)$, BuAc becomes a poor solvent, and its solvent quality for this polymer becomes poorer and poorer as the temperature increases, resulting in phase separation at a certain temperature.

Because the $\chi$ parameter varies with temperature, the chemical potentials in Equations (1) and (2) can be represented as functions of $P, T$ and $\phi$, that is, $\Delta \mu_{i}(\phi, T, P)$. In the liquid-liquid phase-separated state, the chemical potentials of the solvent $(i=1)$ and the polymer $(i=2)$ should satisfy Equations (5) and (6), respectively.

$$
\Delta \mu_{1}\left(\phi^{\prime}, T, P\right)=\Delta \mu_{1}\left(\phi^{\prime \prime}, T, P\right)
$$

$$
\Delta \mu_{2}\left(\phi^{\prime}, T, P\right)=\Delta \mu_{2}\left(\phi^{\prime \prime}, T, P\right)
$$

Here, $\phi^{\prime}$ and $\phi^{\prime \prime}$ are the volume fractions of the polymer in the phaseseparated dilute and concentrated solutions, respectively. For a solution of polymer with a degree of polymerization of $P, \chi$ can be calculated at a given temperature $T$ from Equation (3), and by solving Equations (5) and (6), the values of $\phi^{\prime}$ and $\phi^{\prime \prime}$ for the separated phases can be obtained at that temperature. Through this procedure, binodal curves for $\mathrm{P}(\mathrm{CVE}-\mathrm{MA}) / \mathrm{BuAc}$ of different molecular weights can be computed and are shown as lines in Figure 4. In these calculations, the $P$ values for P(CVE-MA)-1 $\left(M_{\mathrm{w}}=77200\right),-2$ (92 200), -3 (36 400), -4 (17 500) and -5 (7700) were assumed to be $378,451,178,86$ and 38 , respectively. The calculated curves reasonable reproduced the experimental phase diagram, that is, (i) the binodal lines exhibit LCST-type behavior, (ii) the lines shift to lower temperatures as the molecular weight of the polymer increases, and (iii) when $M_{\mathrm{w}}$ is high, the lines exhibit sudden decreases in the lower concentration region and level off in the higher concentration region. The value of $T_{\mathrm{cp}}\left(=132^{\circ} \mathrm{C}\right)$ for $\mathrm{P}(\mathrm{CVE}-\mathrm{MA})-5$ deduced from the mixed BuAc/octane solvent at $1 \mathrm{wt} \%$ is also located near the calculated line. Of course, the present calculation is based on the condition that the polymer is monodisperse, although the polymers used in the experiments have a certain molecular weight distribution. The $M_{\mathrm{w}}$ distribution may be the reason for some observed quantitative discrepancies between the experimental and calculated $T_{\mathrm{cp}}$. For example, the concentration dependence of $T_{\mathrm{cp}}$ for $\mathrm{P}(\mathrm{CVE}-\mathrm{MA})-3$ was broader than the calculated binodal line, and the calculated line for $\mathrm{P}(\mathrm{CVE}-\mathrm{MA})-1$ is located in a lower temperature regime than the experimental results. Despite these discrepancies, the overall trend of $T_{\mathrm{cp}}$ variation with polymer concentration and molecular weight can be reproduced with the $\mathrm{F}-\mathrm{H}$ calculation, which suggests that the LCST-type phase diagram of $\mathrm{P}(\mathrm{CVE}-\mathrm{MA}) / \mathrm{BuAc}$ can be described within the framework of basic F-H theory. However, the negative temperature dependence of the $\chi$ parameter cannot be explained by the original concept for $\chi$, which was based on a van Laar-type segmental interaction between the polymer and the solvent, suggesting that some other specific interactions may exist.

Effect of addition of cosolvent on the $T_{\mathrm{cp}}$ of P(CVE-MA)/BuAc The effect of adding various cosolvents on the $T_{\mathrm{cp}}$ of the $\mathrm{P}(\mathrm{CVE}-\mathrm{MA}) /$ BuAc solution was investigated using $\mathrm{P}(\mathrm{CVE}-\mathrm{MA})-2$ at a fixed polymer concentration of $0.1 \mathrm{wt} \%$. The temperature dependences of $I_{\mathrm{s}}$ in different solvent mixtures are shown in Figure 6. As observed in pure BuAc, the $I_{\mathrm{s}}$ of the polymer solution increased sharply at a certain $T_{\mathrm{cp}}$. The cosolvents benzene, toluene, cyclohexane and 1,2-dichloroethane all caused $T_{\mathrm{cp}}$ to decrease as the amount of cosolvent added to BuAc increased, as shown in Figures $6 \mathrm{a}-\mathrm{d}$, respectively. This phenomenon was also observed in the $\mathrm{P}(\mathrm{CVE}-\mathrm{MA})-5 / \mathrm{BuAc} / n$-octane solutions of Figure 2 and arises because these solvents make the solvent mixture 

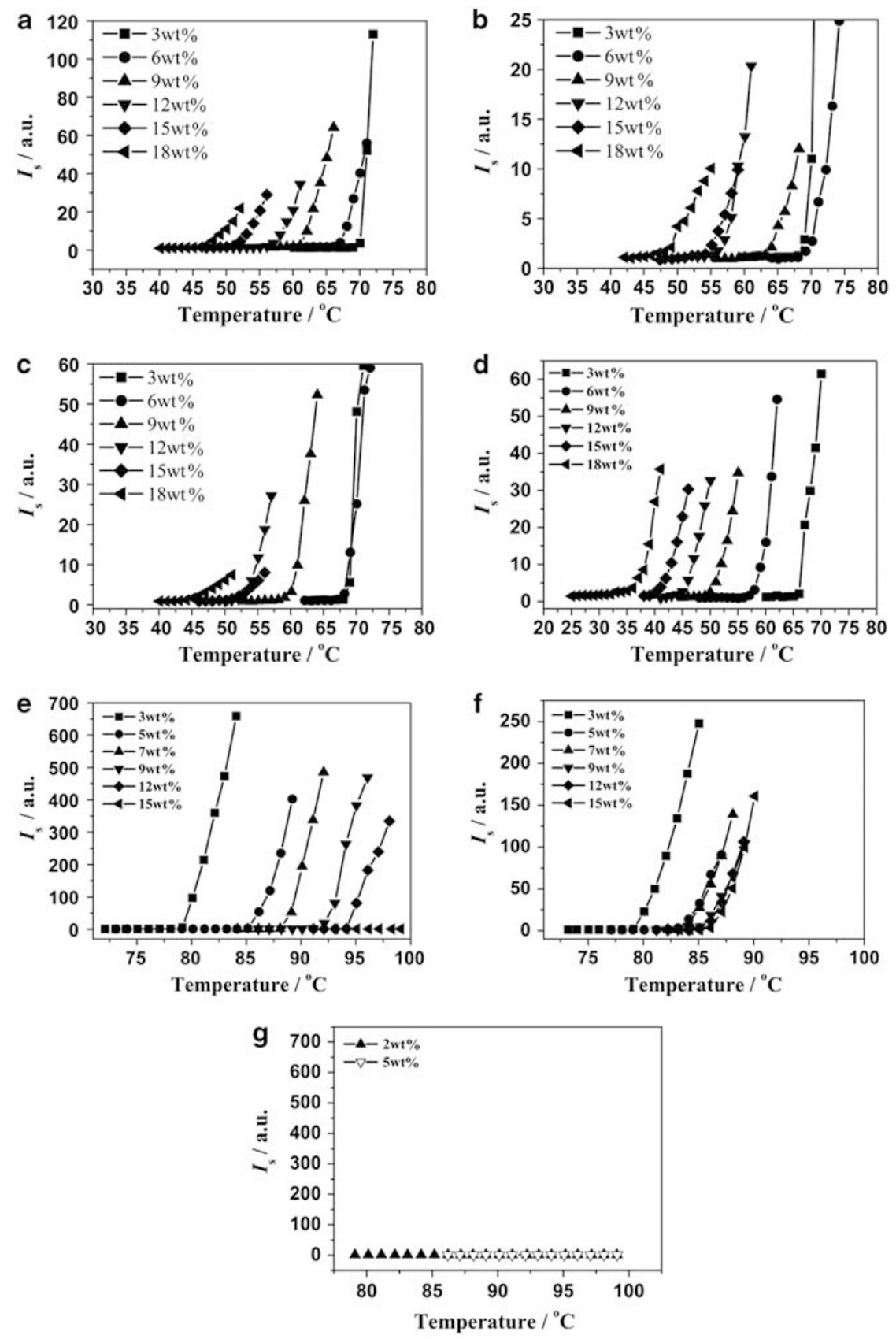

Figure 6 Temperature dependence of $I_{\mathrm{s}}$ of polymer solutions with different amounts of various cosolvents added. (a) Benzene, (b) toluene, (c) 1,2dichloroethane, (d) cyclohexane, (e) 2-hexanone, (f) propyl acetate and (g) dimethylsulfoxide.

more poor than pure BuAc. In other words, these solvents as well as $n$-octane should be non-solvent for P(CVE-MA).

The relationship between $T_{\mathrm{cp}}$ and the added amounts of these solvents is shown in Figure 7. There exists an overall tendency that the $T_{\mathrm{cp}}$ of the polymer solution decreased as the amount of cosolvent increased. In the cases of benzene, toluene and 1,2-dichloroethane, the slopes of the $T_{\mathrm{cp}}$ versus added solvent lines were similar, and the effectiveness of these solvents at reducing $T_{\mathrm{cp}}$ is ranked as follows: 1,2dichloroethane $>$ benzene $>$ toluene. Cyclohexane exhibits the highest effectiveness at reducing $T_{\mathrm{cp}}$, meaning that aliphatic cyclohexane is the least powerful solvent of $\mathrm{P}(\mathrm{CVE}-\mathrm{MA})$ among the solvents in Figure 7.

By contrast, in Figures 6e-g, 2-hexanone, propyl acetate and DMSO were the cosolvents added to the $\mathrm{P}(\mathrm{CVE}-\mathrm{MA}) / \mathrm{BuAc}$ solutions. As 2-hexanone was added to the polymer/BuAc solution, $T_{\mathrm{cp}}$ shifted to higher temperatures until the amount of added 2-hexanone reached $15 \mathrm{wt} \%$, at which no thermoresponsive behavior was observed below $100{ }^{\circ} \mathrm{C}$ (Figure 6e). $T_{\mathrm{cp}}$ shifted to higher temperature slowly as the amount of added propyl acetate to BuAc increased (Figure $6 \mathrm{f}$ ). When DMSO was added, shown in Figure $6 \mathrm{~g}$, the solution remained transparent until $100{ }^{\circ} \mathrm{C}$ without any thermoresponsive behavior, even when the amount of added DMSO reached $2 \mathrm{wt} \%$.

Figure 8 shows the $T_{\mathrm{cp}}$ of the polymer solution as a function of the amount of other added solvents including 2-hexanone and propyl acetate. It is clear that 2-hexanone increased the $T_{\mathrm{cp}}$ of the polymer/ BuAc solution more effectively than propyl acetate. The phenomenon of $T_{\mathrm{cp}}$ increasing as larger amounts of good solvents are added has also 


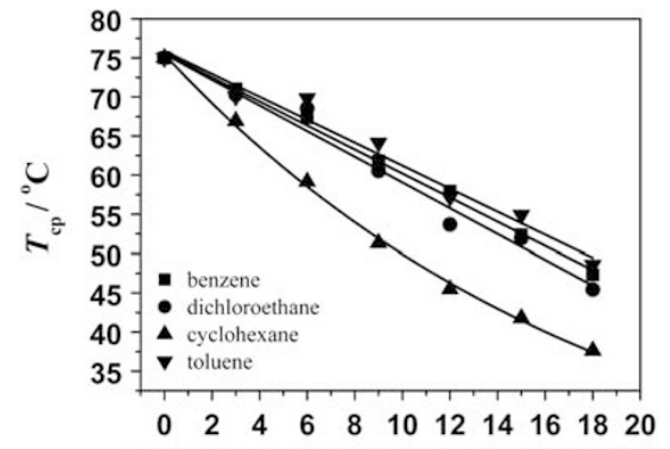

Weight percentage of co-solvent / wt $\%$

Figure $7 T_{\mathrm{cp}}$ of polymer solutions in $n$-butyl acetate with different amounts of the indicated cosolvents added.

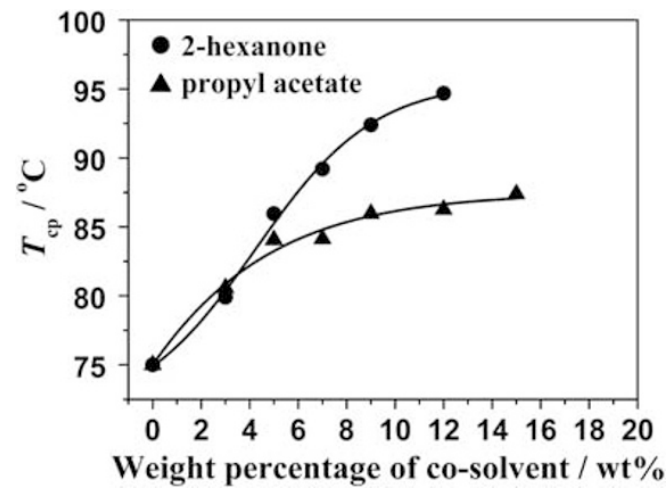

Figure $8 T_{\text {cp }}$ of polymer solutions in $n$-butyl acetate with different amounts of the indicated cosolvents added.

been observed in aqueous poly(vinyl methyl ether) solutions and may arise because the interactions between the good solvents and the polymers are heavily favored over the interaction between the polymer and the original solvent. ${ }^{41}$ The $T_{\mathrm{cp}}$ in Figure 8 may increase because these cosolvents interact with the polymer more strongly than BuAc, and the phenomena in Figures 7 and 8 present clues about the ability of each solvent to dissolve this polymer. Our experiments showed that $\mathrm{P}(\mathrm{CVE}-\mathrm{MA})$ can be dissolved in 2-hexanone and propyl acetate but cannot be dissolved in the solvents shown in Figure 7. Figure $6 \mathrm{~g}$ shows that DMSO, which produced a pink solution after dissolving the polymer, should be the best solvent of $\mathrm{P}$ (CVE-MA) used in this work.

The slope of the curves in Figures 7 and 8 should represent the ability of each solvent to dissolve P(CVE-MA). The values of this slope for each of the tested cosolvents are listed in Table 2. The dielectric constants $(\varepsilon)$ and solubility parameters $(\delta)$ of these solvents are also indicated; the former value relates to the polarity of the solvent, and the latter value is conventionally used to indicate the solubility of the polymer solution. ${ }^{42}$ These lists indicate that the $\delta$ values do not exhibit a linear relationship with the solubility of $\mathrm{P}(\mathrm{CVE}-\mathrm{MA})$. In contrast, the value of the slope seems to increase with $\varepsilon$, with the exception of 1,2-dichloroethane. In Table 2, the polar contribution to the solubility parameter proposed by Hansen, ${ }^{43} \delta_{\mathrm{p}}$, is also listed. $\delta_{\mathrm{p}}$ and $\varepsilon$ exhibit similar relationships with the slope of the curve. In Figure 9, the values of the slope are plotted against $\delta_{\mathrm{p}}$, and a good linear relationship can be seen, with the exception of 1,2-dichloroethane. Therefore, except for 1,2-dichloroethane, we can mention that a solvent's ability to dissolve $\mathrm{P}(\mathrm{CVE}-\mathrm{MA})$ is determined by the polarity of the solvent.
Table 2 Various physical properties of the tested cosolvents

\begin{tabular}{lcccc}
\hline Cosolvent & $\begin{array}{c}\text { Slope } \\
\left({ }^{\mathrm{a}} \mathrm{C} / w \mathrm{w}^{\mathrm{a}}\right)\end{array}$ & $\begin{array}{c}\text { Dielectric } \\
\text { constant } \varepsilon\end{array}$ & $\begin{array}{c}\text { Solubility } \\
\text { parameter } \delta\end{array}$ & $\begin{array}{c}\text { Polar term in } \\
\text { solubility parameter } \delta_{p}\end{array}$ \\
\hline Cyclohexane & -2.1 & 2.02 & 16.8 & 0 \\
1,2-Dichloroethane & -1.8 & 10.4 & 20.9 & 7.4 \\
Benzene & -1.7 & 2.27 & 18.6 & 0 \\
Toluene & -1.6 & 2.38 & 18.2 & 1.4 \\
Propyl acetate & 1.6 & $\sim 5.5^{\mathrm{b}}$ & $17.8^{\mathrm{b}}$ & $4.5^{\mathrm{b}}$ \\
2-Hexanone & 2.0 & $\sim 17^{\mathrm{c}}$ & 17 & 6.1 \\
DMSO & Very large & 46.5 & 26.6 & 16.4
\end{tabular}

Abbreviation: DMSO, dimethyl sulfoxide.

aslope of the plot of $T_{\mathrm{cp}}$ versus cosolvent's weight fraction in Figures 7 and 8 .

${ }^{b}$ Approximate value from ethyl acetate and $n$-butyl acetate.

${ }^{\mathrm{c} A p p r o x i m a t e}$ value from 2-butanone and cyclohexanone.

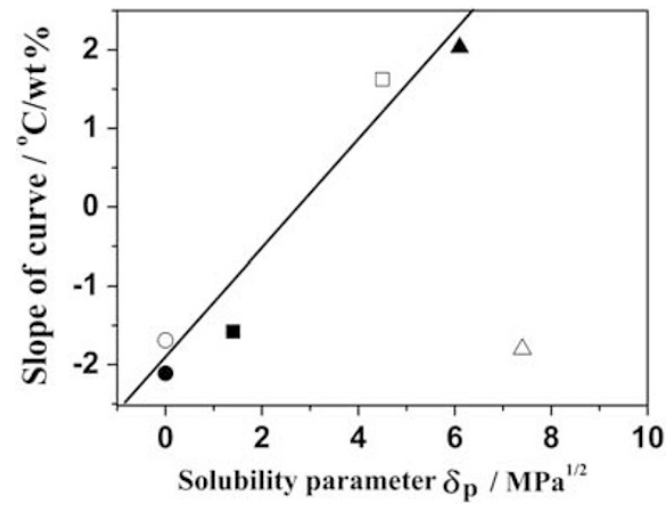

Figure 9 Relationship between the slope of the curve of $T_{\mathrm{cp}}$ versus the added cosolvent amounts evaluated from Figures 7 and 8 and the polar contribution to the solubility parameter $\left(\delta_{\mathrm{p}}\right)$ of the cosolvent. (•) Cyclohexane, $(\bigcirc)$ benzene, $(\boldsymbol{\square})$ toluene, $(\square)$ propyl acetate, ( $(\boldsymbol{\Delta})$ 2-hexanone and $(\Delta)$ 1,2-dichloroethane. The straight line is a guide for the eye.

As reported in our recent studies, ${ }^{21,44}$ tetrahydrofuran is a good solvent of $\mathrm{P}(\mathrm{CVE}-\mathrm{MA})$, whereas $n$-hexane is a non-solvent. Some polar interaction between $\mathrm{P}(\mathrm{CVE}-\mathrm{MA})$ and the solvent is likely to be an important factor for solubilization. This hypothesis seems reasonable because $\mathrm{P}(\mathrm{CVE}-\mathrm{MA})$ contains polar ether and carboxylic anhydride groups and the good solvents also contain oxygen atoms in their chemical structures, whereas the non-solvents are oxygen-free non-polar solvents. The LCST behavior of $\mathrm{P}(\mathrm{CVE}-\mathrm{MA}) / \mathrm{BuAc}$ suggests that the polar interaction between the polymer and the solvent becomes weak as the temperature increases, which results in the segregation and precipitation of $\mathrm{P}(\mathrm{CVE}-\mathrm{MA})$. Because of chemical structure similarities, 1,2-dichloroethane would prefer to interact with the 2-chloroethyl group in $\mathrm{P}(\mathrm{CVE}-\mathrm{MA})$ and prevent the interaction between the polymer and $\mathrm{BuAc}$, which might be the reason that 1,2-dichloroethane did not follow the linear relationship in Figure 9.

\section{CONCLUSION}

Novel LCST-type phase behavior of polymer solutions in common organic media under mild conditions has been investigated. Alternating copolymers of CVE and MA produced an LCST-type solution when dissolved in BuAc, and the $T_{\mathrm{cp}}$ values of the higher molecular weight polymers were much lower than the boiling temperature of the solvent. As the $M_{\mathrm{w}}$ of the polymers increased, the $T_{\mathrm{cp}}$ of the polymer solution decreased. The experimental LCST-type phase diagram of this polymer solution can be reasonably described by F-H theory. The $T_{\mathrm{cp}}$ 
of the polymer solution in BuAc can also be tuned by adding cosolvents. Adding non-solvent decreases the $T_{\mathrm{cp}}$, whereas adding proper good solvents increases the $T_{\mathrm{cp}}$ of the polymer/BuAc solution. This increase can be ascribed to the polar interaction between $\mathrm{P}(\mathrm{CVE}-$ MA) and the solvent. Effects that strengthen the polar interaction between the polymer and the solvents are inclined to increase the $T_{\mathrm{cp}}$ of the polymer solution.

To understand the LCST behavior of P(MA-CVE)/BuAc systems, dilute polymer solution properties such as the second virial coefficient $A_{2}$ and its temperature dependence measured through precise light scattering or viscosity measurements around the evaluated $\Theta$ temperature $\left(=60^{\circ} \mathrm{C}\right)$ will offer useful information. Further investigations of these novel polymer solutions with LCST-type phase behavior will be reported in future studies.

Finally, we should mention that this copolymer can be conveniently chemically modified because it has functional alkyl chloride and carboxylic anhydride groups. Thus, research and development can be expected to discover applications of the tunable LCST thermoresponsive behavior under mild conditions of this novel polymer solution in organic solvent.

1 Dimitrov, I., Trzebicka, B., Müller, A. H. E., Dworak, A. \& Tsvetanov, C. B. Thermosensitive water-soluble copolymers with doubly responsive reversibly interacting entities. Prog. Polym. Sci. 32, 1275-1343 (2007).

2 Liu, R., Fraylich, M. \& Saunders, B. R. Thermoresponsive copolymers: from fundamental studies to applications. Colloid Polym. Sci. 287, 627-643 (2009).

3 Hchild, H. G. Poly( $N$-isopropylacrylamide): experiment, theory and application. Prog. Polym. Sci. 17, 163-249 (1992).

4 Ueki, T. \& Watanabe, M. Lower critical solution temperature behavior of linear polymers in ionic liquids and the corresponding volume phase transition of polymer gels. Langmuir 23, 988-990 (2007).

5 Ueki, T., Karino, T., Kobayashi, Y., Shibayama, M. \& Watanabe, M. Difference in lower critical solution temperature behavior between random copolymers and a homopolymer having solvatophilic and solvatophobic structures in an ionic liquid. J. Phys. Chem. B $111,4750-4754$ (2007).

6 Kodama, K., Nanashima, H., Ueki, T., Kokubo, H. \& Watanabe, M. Lower critical solution temperature phase behavior of linear polymers in imidazolium-based ionic liquids: effects of structural modifications. Langmuir 25, 3820-3824 (2009).

7 Ueki, T. \& Watanabe, M. Macromolecules in ionic liquids: progress, challenges, and opportunities. Macromolecules 41, 3739-3749 (2008).

8 Siow, K. S., Delmas, G. \& Patterson, D. Cloud-point curves in polymer solutions with adjacent upper and lower critical solution temperatures. Macromolecules 5, 29-34 (1972).

9 Konno, S., Saeki, S., Kuwahara, N., Nakata, M. \& Kaneko, M. Upper and lower critical solution temperatures in polystyrene solutions. IV. Role of configurational heat capacity. Macromolecules 8, 799-804 (1975).

10 Bae, Y. C., Lambert, S. M., Soane, D. S. \& Prausnitz, J. M. Cloud-point curves of polymer solutions from thermooptical measurements. Macromolecules 24, 4403-4407 (1991).

11 Patterson, D., Delmas, G. \& Somcynsky, T. A comparison of lower critical solution temperatures of some polymer solutions. Polymer 8, 503-516 (1967).

12 Burchard, W. Thermodynamic solution properties of three polymers exhibiting lower critical solution temperature. Polymer 10, 467-475 (1969).

13 Cowie, J. M. G. \& Swinyard, B. Location of three critical phase boundaries in poly(acrylic acid)-dioxane solutions. Polymer 31, 1507-1513 (1990).

14 Cowie, J. M. G., Maconnachie, A. \& Ranson, R. J. Phase equilibria in cellulose acetate-acetone solutions. The effect of the degree of substitution and molecular weight on upper and lower critical solution temperatures. Macromolecules 4, 57-61 (1971).

15 Jang, J. G. \& Bae, Y. C. Phase behaviors of binary polymer solutions: the extended lattice fluid model. J. Appl. Polym. Sci. 70, 1143-1150 (1998).

16 Wang, F., Saeki, S. \& Yamaguchi, T. Absolute prediction of upper and lower critical solution temperatures in polymer/solvent systems based on corresponding state theory. Polymer 40, 2779-2785 (1999).

17 Patterson, D. Free volume and polymer solubility. A qualitative view. Macromolecules 2, 672-677 (1969).

18 Migisawa, M., Ohnishi, K. \& Sawada, H. Preparation of novel fluoroalkyl-end-capped 2-acrylamido-2-methylpropanesulfonic acid cooligomeric nanoparticles containing adamantane units possessing a lower critical solution temperature characteristic in organic media. Langmuir 23, 5848-5851 (2007).

19 Kuroiwa, K., Shibata, T., Takada, A., Nemoto, N. \& Kimizuka, N. Heat-set gel-like networks of lipophilic $\mathrm{Co}(\mathrm{II})$ triazole complexes in organic media and their thermochromic structural transitions. J. Am. Chem. Soc. 126, 2016-2021 (2004).

20 Seno, K.- I., Kanaoka, S. \& Aoshima, S. Synthesis and LCST-type phase separation behavior in organic solvents of poly(vinyl ethers) with pendant imidazolium or pyridinium salts. J. Polym. Sci. Part A Polym. Chem. 46, 5724-5733 (2008).

21 Liu, Z., Guo, Y. \& Inomata, K. Lower critical solution temperature behavior of poly(2-chloroethyl vinyl ether-alt-maleic anhydride) in organic media. Polym. J. 42, 901-904 (2010).

22 Inomata, K., Kasuya, M., Sugimoto, H. \& Nakanishi, E. Effect of helix-coil transition on association behavior of both-ends hydrophobically-modified water-soluble polypeptide. Polymer 46, 10035-10044 (2005).

23 Castelvetro, V., Pittaluga, G. B. \& Ciardelli, F. Multifunctional poly(vinyl ethers) by controlled cationic polymerization in a fluorinated solvent. Macromol. Chem. Phys. 202, 2093-2103 (2001).

24 Nukyen, O. \& Ingrisch, S. Block copolymers from isobutyl vinyl ether and 2-chloroethyl vinyl ether. Macromol. Chem. Phys. 199, 607-612 (1998).

25 Heischkel, Y. \& Schmidt, H.- W. Synthesis of ABC-triblock copolymers for light emitting diodes. Macromol. Chem. Phys. 199, 869-880 (1998).

26 Bennevault, V., Peruch, F. \& Deffieux, A. Influence of various proton traps on the bifunctional cationic polymerization of chloroethyl vinyl ether mediated by $\alpha$-iodo ether/ zinc dichloride. Macromol. Chem. Phys. 197, 2603-2613 (1996).

27 Schappacher, M. \& Deffieux, A. New comblike copolymers of controlled structure and dimensions obtained by grafting by polystyryllithium onto poly(chloroethyl vinyl ether) chains. Macromol. Chem. Phys. 198, 3953-3961 (1997).

28 Hall, H. K. Jr Bond-forming initiation in spontaneous addition and polymerization reactions of alkenes. Angew. Chem. Int. Ed. Engl. 22, 440-445 (1983).

29 Fujimori, K., Organ, P. P., Costigan, M. J. \& Craven, I. E. Relative reactivity of free monomers and donor-acceptor complex in alternating copolymerization of isobutyl vinyl ether with maleic anhydride from the rate of polymerization. J. Macromol. Sci. Chem. A23, 647-655 (1986).

30 Hallensleben, M. L. Elektron-donator-akzeptor-komplexe und polymerisation. III. Über die copolymerisation von maleins äureanhydrid mit isomeren butylvinyl äthern. Makromol. Chem. 144, 267-281 (1971).

31 Braun, D., Schacht, M., Elsässer, H. \& Tüdős, F. Alternating terpolymerization of three non-homopolymerizable monomers. Macromol. Rapid Commun. 18, 335-342 (1997).

$32 \mathrm{Ha}, \mathrm{N}$. T. H., Fujimori, K., Henry, P. C. \& Tucker, D. J. Assignment of ${ }^{13} \mathrm{C}$ NMR chemical shift and microstructure of copolymers of 2-chloroethyl vinyl ether-maleic anhydride and n-butyl vinyl ether-maleic anhydride. Polym. Bull. 43, 81-85 (1999).

33 Den, J., Shi, Y., Jiang, W., Peng, Y., Lu, L. \& Cai, Y. Facile synthesis and thermoresponsive behaviors of a well-defined pyrrolidone based hydrophilic polymer. Macromolecules 41, 3007-3014 (2008).

34 Xia, Y., Yin, X., Burke, N. A. D. \& Stölver, H. D. H. Thermal response of narrow-disperse poly ( $\mathrm{N}$-isopropylacrylamide) prepared by atom transfer radical polymerization. Macromolecules 38, 5937-5943 (2005).

35 Yamamoto, S.- I., Pietrasik, J. \& Matyjaszewski, K. The effect of structure on the thermoresponsive nature of well-defined poly(oligo(ethylene oxide) methacrylates) synthesized by ATRP. J. Polym. Sci. Part A Polym. Chem. 46, 194-202 (2008).

36 Gao, J., Zhai, G., Song, Y. \& Jiang, B. Multidimensionally stimuli-responsive phase transition of aqueous solutions of poly(( $N, N$-dimethylamino) ethyl methacrylate) and poly( $N, N$-dimethyl- $N$-(methacryloyl) ethyl ammonium butane sulfonate). J. Appl. Polym. Sci. 107, 3548-3556 (2008).

37 Yamamoto, K., Serizawa, T. \& Akashi, M. Synthesis and thermosensitive properties of poly[( $\mathrm{N}$-vinylamide)-co-(vinyl acetate)]s and their hydrogels. Macromol. Chem. Phys. 204, 1027-1033 (2003)

38 Mori, T., Shiota, Y., Minagawa, K. \& Tanaka, M. Alternative approach to the design of thermosensitive polymers: the addition of hydrophobic groups to the ends of hydrophilic polyether. J. Polym. Sci. Part A Polym. Chem. 43, 1007-1013 (2005).

39 Hua, F., Jiang, X., Li, D. \& Zhao, B.J. Well-defined thermosensitive, water-soluble polyacrylates and polystyrenics with short pendant oligo(ethylene glycol) groups synthesized by nitroxide-mediated radical polymerization. J. Polym. Sci. Part A Polym. Chem. 44, 2454-2467 (2006).

40 Shultz, A. R. \& Flory, P. J. Phase equilibria in polymer-solvent systems. J. Am. Chem. Soc. 74, 4760-4767 (1952)

41 Schild, H. G., Muthukumar, M. \& Tirrell, D. A. Cononsolvency in mixed aqueous solutions of poly( $N$-isopropylacrylamide). Macromolecules 24, 948-952 (1991).

42 Grulke, E. A. 'Solubility parameter values'. in Polymer Handbook, 4th edn. (eds Brandrup, J. et al.) Ch.VII, 675 (Wiley, New York, 1999).

43 Hansen, C. M. Universality of the solubility parameter. Ind. Eng. Chem. Prod. Res. Dev. 8, 2-11 (1969).

44 Liu, Z., Guo, Y. \& Inomata, K. Reversible thermoresponsive behavior of poly(2chloroethyl vinyl ether-alt-maleic anhydride) in mixed solvent of tetrahydrofuran/ hexane. Colloid Polm. Sci. (e-pub ahead of print; doi:10.1007/s00396-011-2395-y). 